\title{
Aplicação do método QDF na avaliação do perfil do consumidor de melão amarelo
}

\author{
Consumer profile evaluation by quality function development for melon
}

\author{
Camila ABRAHÃO ${ }^{1}$, Ana Carolina Almeida MIGUEL ${ }^{1 \star}$, João Ricardo Pecini Stein DIAS ${ }^{1}$, \\ Marta Helena Fillet SPOTO $^{1}$, Paula Porrelli Moreira da SILVA ${ }^{1}$
}

\section{Resumo}

A busca pela longevidade e a procura por alimentos mais saudáveis fizeram com que os consumidores se tornassem cada vez mais exigentes. Diante disso, procurou-se estabelecer o comportamento de compra dos consumidores de melão no Mercado Municipal de Piracicaba (SP) através do método de Desdobramento da Função Qualidade (QFD) e, com base nas respostas obtidas nos questionários aplicados, traçouse o perfil dos consumidores, destacando-se suas preferências, costumes, reclamações e exigências. Verificou-se que é a mulher que realiza as compras do melão, com preferência pelo consumo na forma in natura. Encontrou-se insatisfação de 42,8\% dos entrevistados quanto à qualidade do melão, sendo o sabor aguado a principal causa de descontentamento. Logo, a qualidade do melão não correspondia àquela indicada pelos consumidores (casca sem defeitos, coloração amarela característica da variedade, textura firme, suculento, de preço acessível, garantia de qualidade e gosto doce). Diante da insatisfação dos consumidores e considerando-se que o melão é consumido preferencialmente in natura, deve-se atentar para a preservação da sua aparência e qualidade sensorial. A opinião dos consumidores deve ser considerada na tentativa de identificar os pontos que devem ser melhorados dentro da cadeia de comercialização a fim de minimizar as perdas e promover a melhoria e a manutenção da qualidade do produto final.

Palavras-chave: Cucumis melo; padrões de qualidade; consumo in natura.

\begin{abstract}
The search for longevity and the demand for healthy food have made consumers more conscious. A study was carried out to evaluate the purchasing habits of melon consumers in the Municipal Market of Piracicaba (São Paulo State, Brazil) by the Quality Function Development (QFD) Method. With the answers to the questionnaire, it was possible to determine the consumers' preferences, habits, complaints, and demands. It was verified that women are the consumers and that melons are consumed raw. $42.8 \%$ of the interviewees complained about the quality, and the watery taste of melons was the major complaint. The quality of the melons displayed does not meet customer expectations (damage, variety color, firmness, succulence, accessible price, quality guarantee, and sweetness). Due to the customers' complaints and considering their preference for fresh melons, special attention must be given to the appearance and sensory quality. The opinion of the consumers must be considered in order to identify the characteristics that should be improved to minimize losses, promote improvement, and maintain the final product quality.
\end{abstract}

Keywords: Cucumis melo; quality standards; fresh market.

\section{Introdução}

Com a preocupação do consumidor atual em relação a dietas balanceadas, ricas em alimentos vegetais, decorrente de seu maior grau de informação, ocorre o aumento no consumo de frutas e hortaliças, produtos saudáveis, frescos, com menores teores de colesterol e outras substâncias indesejáveis (MACHADO et al., 1996), aumentando a demanda por tais produtos e pressionando sua produção.

O melão é cultivado em todas as regiões do Brasil, com destaque para o Nordeste que é o maior produtor do país. Em 2004, a produção brasileira foi de 340.683 toneladas de frutos, sendo que a região Nordeste foi responsável por 320.819 toneladas, seguida da Sul (16.717 toneladas), Sudeste (1.373 toneladas), Norte (1.161 toneladas) e Centro-Oeste (793 toneladas) (AGRIANUAL, 2007).
O melão é muito apreciado por grande parte dos consumidores, mas, por outro lado, esta é uma das olerícolas comercializadas que apresenta grande dificuldade de escolha pelo consumidor, principalmente pela aparência externa. Nesse sentido, é necessário ouvir as opiniões e as necessidades dos clientes, no que se refere ao melão oferecido e comercializado in natura e, a partir do levantamento dessas informações, determinar as características desejadas pelo consumidor. Segundo Mattar (1999), a forma tradicional para coleta de dados primários é por meio da comunicação direta com o detentor dos dados, sendo o dado obtido pela declaração do próprio respondente, caracterizando o uso de entrevistas e questionários. Ferreira et al. (2000) relataram que o uso de questionários como meio de coletar informações junto aos consumidores apresenta

Recebido para publicação em 27/9/2007

Aceito para publicação em 15/9/2008 (002890)

${ }^{1}$ Alimentos e Nutrição, Departamento de Agroindústria, Escola Superior de Agricultura Luiz de Queiroz, Av. Pádua Dias, nº 11, CP 9, CEP 13418-900, Piracicaba, SP, E-mail:anaamiguel@yahoo.com.br

${ }^{*}$ A quem a correspondência deve ser enviada 
menor custo em comparação aos testes de mercado e pode ser realizado em períodos de tempo relativamente curtos.

Os consumidores indicam a estratégia de mercado para melhoria na apresentação do produto a ser adotada pelo setor alimentício e pelos produtores agrícolas. Sabe-se que a satisfação ou não do consumidor pode interferir nas decisões de compra (ANDREUCCETTI; FERREIRA; TAVARES, 2005). Segundo Iasbeck e Oliveira (2005), a satisfação do consumidor é função das expectativas atendidas na ocasião da compra. Se o desempenho do produto adquirido não atende às expectativas, o consumidor mostra-se insatisfeito. Caso contrário, se o desempenho satisfaz as expectativas, o consumidor estará satisfeito e manterá fidelidade em relação ao produto adquirido.

A produção de frutas é suficiente para suprir o mercado, sinalizando que o desafio é levar até a mesa do consumidor produtos com as características por ele esperadas. Segundo Vilela e Macedo (2000), os setores envolvidos na comercialização devem observar as tendências de mercado para identificar quais atributos dos bens têm maior valor sob a ótica do consumidor final, para aproveitar as reais oportunidades de mercado.

Sabe-se que testes para a determinação de parâmetros que determinem à qualidade do melão são conhecidos, no entanto pouco se sabe a respeito das exigências do consumidor, ou melhor, não há uma relação estabelecida entre as informações tecnológicas e as opiniões das características ideais. Assim, é necessário conhecer as opiniões e necessidades dos clientes a respeito do melão consumido in natura e, a partir do levantamento dessas informações, determinar as características da fruta desejadas pelo consumidor. Em vista disso, este trabalho teve como objetivos identificar o perfil dos consumidores de melão quanto às preferências, exigências, reclamações e comportamento de compra.

\section{Material e métodos}

Inicialmente o projeto foi avaliado pelo Comitê de Ética em Pesquisa, na Faculdade de Saúde Pública da Universidade de São Paulo (USP/FSP) e foi aprovado por estar de acordo com a Resolução 196/96 do Conselho Nacional de Saúde.

A pesquisa foi realizada no Mercado Municipal de Piracicaba (SP) no mês de agosto de 2005, onde foram realizadas entrevistas individuais com 95 clientes, segundo o método QFD (CHENG et al., 1995). O tamanho da amostragem foi determinado através da equação apontada por Cochran (1977) para amostragem aleatória simples, considerando $t=2 \mathrm{e}$ $\mathrm{r}=10 \%$, que leva ao número de unidades (pessoas) que devem ser entrevistadas para se estimar a média com uma aproximação de $10 \%(\mathrm{r}=10 \%)$ e uma possibilidade de erro em $20(\mathrm{t}=2)$. Adotaram-se esses valores por se considerar que forneceriam resultados satisfatórios (MARCOS, 2001). Consideraram-se como público alvo, os consumidores, ou seja, as pessoas que se encontravam nas bancas de melões, não se privilegiando quaisquer grupos de consumidores, conforme indicado por Cheng et al. (1995). Optou-se por realizar a entrevista de forma individual, utilizando questionário contendo oito perguntas para a determinação do perfil dos consumidores, destacando-se: 1) dados pessoais; 2) motivo da compra; 3 ) determinação das variedades conhecidas pelos consumidores; 4) grau de satisfação quanto à qualidade do melão; 5) características observadas no momento da compra; 6) frequência de compra; 7) conceito de produto ideal; 8) se o consumidor pagaria um valor mais elevado por um melão de qualidade. Foi realizada uma análise gráfica dos dados e definiu-se o grau de importância dos itens citados pelos consumidores, considerando-se a classe modal, a que mais vezes foi citada, como grau requerido no item. De posse dos dados definiu-se a qualidade planejada para o melão e aplicou-se o método afetivo utilizando-se melões disponíveis no Mercado Municipal de Piracicaba que continham as características indicadas pelo consumidor. Foram utilizados 15 melões, os quais foram levados ao Departamento de Agroindústria, Alimentos e Nutrição da ESALQ/USP, Piracicaba (SP), onde foram lavados com detergente a fim de retirar as sujicidades mais grosseiras, sendo, em seguida, imersos em solução de hipoclorito de sódio a 100 ppm por 10 minutos para evitar contaminação durante o corte.

Terminada esta etapa, 12 melões foram descascados, cortados em cubos de $3 \mathrm{~cm}$ de aresta, sendo, então, distribuídos em copos de tereftalato de polietileno (PET) munidos de tampa que acomodaram $50 \mathrm{~g}$ de melão.

Após o processamento, os melões foram armazenados a $5{ }^{\circ} \mathrm{C}$ por um dia, a fim de manter as características originais do produto. No dia seguinte, as amostras foram levadas ao Mercado Municipal de Piracicaba em isopor para serem apresentadas para 100 consumidores, aos quais foi solicitado que avaliassem os melões cortados em cubos de $3 \mathrm{~cm}$ de aresta e atribuíssem, em escala hedônica (MEILGAARD; CIVILLE; CARR, 1991), notas de 1 (desgostei extremamente) a 9 (gostei extremamente), para os atributos, coloração, sabor, suculência e aparência externa. Para a avaliação deste último item, três melões foram dispostos em bandeja de cloreto de polivinila sobre a bancada de prova.

\section{Resultados e discussão}

Verificou-se que $71,4 \%$ dos entrevistados eram do sexo feminino, indicando que a mulher ainda é a responsável pelas compras de alimentação na família, que, segundo Marcos (2001), são mais exigentes e demonstram maior atenção aos detalhes, com maior cuidado na escolha do produto, fato observado neste levantamento. Nos dias de pesquisa, observou-se que o motivo pelo qual o consumidor é levado a adquirir melão, foi a maior intenção de consumo na forma in natura, correspondendo a $85 \%$ da preferência. Enquanto que 34,3\% dos consumidores compram melão para o preparo de sucos e 5,7\% adquirem melão para a confecção de doces. A preferência do consumidor de melão para consumo in natura, reforça a ideia de garantir a manutenção da qualidade do produto, haja vista que a aparência constitui um fator decisivo da compra (KADER, 2002).

A maioria dos consumidores entrevistados $(82,9 \%)$ tinha conhecimento das variedades comercializadas, sendo as mais citadas pelos consumidores: a amarelo, indicada por $65,7 \%$ dos entrevistados; $22,8 \%$ conheciam a caipira; e apenas $8,6 \%$ a orange. Ao serem questionados sobre a preferência, 31,4\% dos entrevistados afirmaram que preferiam o melão amarelo; $14,3 \%$ elegeram o melão caipira; e $17,1 \%$ afirmaram que não 
tinham preferência. Quando indagados sobre o motivo da preferência do melão amarelo, os consumidores mencionaram a suculência e o sabor agradável. Entre os que preferiam o caipira, os entrevistados destacaram a doçura.

Durante o período da pesquisa, $42,8 \%$ dos consumidores estavam insatisfeitos com a qualidade do melão, apontando o sabor aguado como a principal causa de descontentamento, seguido de frutos sem sabor e daqueles contendo podridões internas, conforme descrito na Figura 1. O melão, como a maioria das hortaliças, é classificado como perecível. Essa característica, quando aliada ao manuseio inadequado pelos membros da cadeia de comercialização, pode gerar prejuízos tanto aos agentes de comercialização quanto ao consumidor final. Rij e Ross (1988) relatam que, em melões, o apodrecimento, a descoloração da superfície, a injúria pelo frio e o superamadurecimento são as maiores causas de perdas pós-colheita durante a comercialização, as quais influenciam em alterações fisiológicas, metabólicas e de qualidade. A exposição do produto nas gôndolas do varejo, por tempo prolongado, contribui para o aumento das perdas. Este fato é capaz de promover a diminuição da qualidade do produto, gerando insatisfação por parte dos consumidores (SHEWFELT, 2000). Somente através do estabelecimento de um novo sistema de padrões, procurando traduzir e transmitir as exigências dos consumidores em características de qualidade poder-se-á atender às suas expectativas (ANDREUCCETTI; FERREIRA; TAVARES, 2005).

Na hora de comprar o melão, alguns entrevistados tomavam a hortaliça na mão e listavam as características que gostariam que estivessem presentes e indicavam as que não gostariam de encontrar, muitas vezes indicando o fruto que comprariam e o que recusariam. Essas características foram resumidas e agrupadas na Figura 2. Observa-se que a aparência foi uma das características mais indicadas pelos entrevistados, incluindo a coloração característica da variedade, representando 31,5\%, o que vem ao encontro do enunciado por Kader (2002), no qual $83 \%$ da decisão de adquirir ou rejeitar um produto é determinado pela aparência ou condição em que este se encontra.

A prática de apertar o melão para verificar sua integridade é realizada por $22,8 \%$ dos consumidores; $5,7 \%$ observam se há defeitos na casca do melão, incluindo danos mecânicos (perfurações, amassados) ou qualquer anormalidade externa evidente. O preço é observado por 11,4\% dos entrevistados, concordando com a pesquisa feita pelo IBGE nas nove Regiões Metropolitanas do País, nos vários pontos de varejo disponíveis, a qual revelou que as hortaliças encabeçam a lista de cortes promovidos pela família brasileira diante da necessidade de conter despesas, sendo gastos entre $5 \%$ e $20 \%$ do gasto com alimentos em hortaliças (HORTALIÇA, 1999). Verificou-se também que $11,4 \%$ dos consumidores avaliam a qualidade do melão na ocasião de compra, indicando que o público está preocupado com a questão da saúde e da segurança, desejando adquirir um produto em que possa confiar.

Baseado na coleta de dados, definiu-se o grau de importância seguindo-se o modelo de Cheng et al. (1995), com uma escala balanceada e com ponto neutro, de cada item avaliado, ou seja: 1) aparência externa (ausência de defeitos, de frutas machucadas ou com alguma lesão); 2) coloração - característica da variedade (amarelo); 3) textura (firmeza, suculência); 4) preço; 5) garantia de qualidade; 6) gosto doce.

O grau de importância atribuído pelos entrevistados à aparência externa do melão amarelo, está representado na Tabela 1 , onde se observa que a maioria das pessoas (31) considera este item "muito importante" e $24 \%$ consideram a aparência externa "importante”.

Em relação à coloração característica da variedade, pode-se dizer que este item é considerado relevante na hora da compra (Tabela 1), pois 55\% dos entrevistados afirmaram que é "muito importante" a "importante". Estes resultados concordam com o enunciado por Kays (1991), que a coloração é o principal parâmetro de qualidade, pois os consumidores já desenvolveram uma relação positiva entre a cor e a qualidade máxima do produto.

Quanto à avaliação da firmeza (item Textura), os consumidores do Mercado Municipal de Piracicaba indicaram que este atributo apresenta elevado grau de importância, sendo as classes "muito importante" e "importante" as mais citadas (Tabela 1). Segundo Chitarra e Alves (2001), as características externas de qualidade percebidas pelo tato e pela visão são

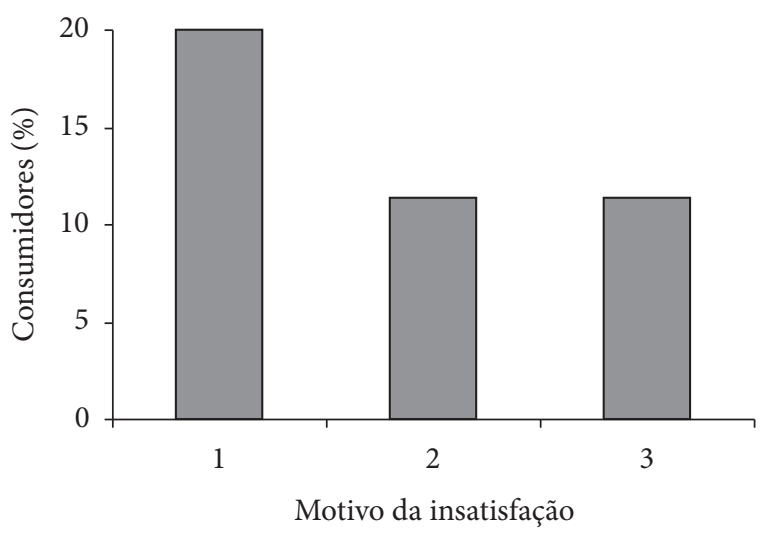

Figura 1. Motivos da insatisfação do consumidor em relação ao melão. 1 = melão aguado, 2 = melão sem sabor, 3 = frutos com podridões.

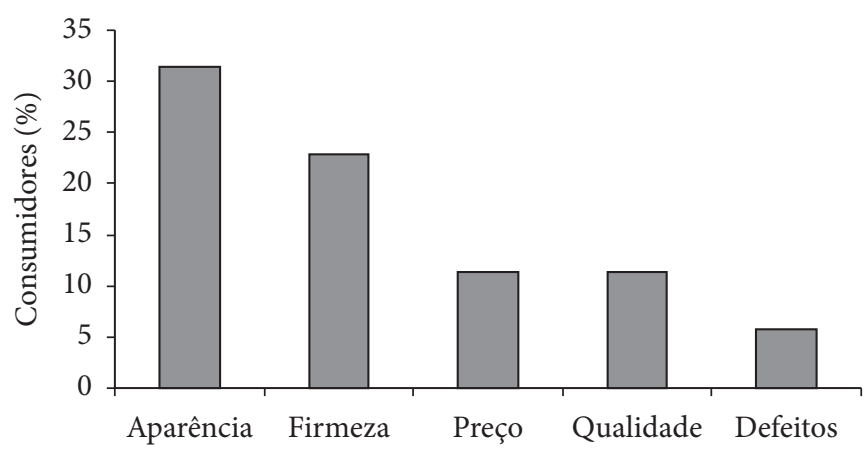

Figura 2. Características observadas pelos consumidores entrevistados no Mercado Municipal de Piracicaba, no momento da compra de melão. 
importantes na diferenciação do produto, particularmente na decisão de compra.

Para a avaliação da suculência (textura), foi observado que as classes "muito importante" e "importante" foram as mais citadas pelos consumidores (Tabela 1), o que já era de se esperar já que a maioria dos consumidores consome o melão na forma in natura.

A frequência do item "preço" avaliado no Mercado Municipal de Piracicaba, cresce à medida que se eleva o grau de importância (Tabela 1). Verificou-se que as classes "muito importante" e "importante" obtiveram maior frequência de respostas que a soma das outras classes.

A Tabela 1 indica o grau de importância para o item garantia de qualidade. Cinquenta e oito entrevistados consideram a garantia de qualidade de "muito importante" a "importante" e apenas dois consumidores afirmaram que na ocasião de compra não levam em consideração a presença de certificado de origem do produto.

A avaliação do item "gosto doce" indicou que a maioria dos consumidores (59) considera esta característica "importante" e "muito importante" (Figura 1), indicando que a doçura é relevante na qualidade da fruta. Estes resultados estão de acordo com os comprovados por Cohem e Hicks (1986), que verificaram correlação significativa $(P=0,1 \%)$ entre a doçura e a aceitação; e justificam a preferência dos entrevistados em consumirem o melão in natura.

Quanto à frequência de compra do melão, identificou-se que $2,8 \%$ o fazem diariamente; $28,6 \%$, uma vez por semana; $2,8 \%$, duas vezes; $11,4 \%$, a cada quinze dias; $14,3 \%$, uma vez por mês; $2,8 \%$, a cada dois meses; $20 \%$, a cada três meses; e $11,4 \%$, raramente. A maior frequência de compra é realizada por pessoas na faixa etária entre 20 e 40 anos (60,0\%), evidenciando a preocupação com relação à saúde. Tais informações são importantes tanto aos varejos (tipo quitanda e sacolões) quanto às redes de supermercado, pois podem constituir uma logística de venda que atenda à demanda e satisfaça os consumidores.

Os consumidores foram questionados sobre o que seria, na opinião deles, um melão ideal para consumo. Eles mencionaram que seria um fruto que apresentasse casca sem defeitos, coloração amarela característica da variedade, textura firme, suculento, preço baixo (ou justo ao produto), qualidade garantida pelo vendedor e gosto doce.

Dos consumidores, $77,1 \%$ alegaram que, se o melão estivesse com o aspecto ideal por eles apontado, pagariam um preço mais elevado; e 22,9\% disseram que não pagariam. De acordo com Owen, Griffith e Wright (2002), os consumidores apresentam uma faixa de aceitação de preços do melão e são sensíveis às bruscas alterações.

$\mathrm{Na}$ avaliação da satisfação do consumidor, foi aplicado o teste afetivo, utilizando frutos que continham as seguintes características: ótima aparência externa, sem defeitos; coloração característica da variedade (amarela); textura firme; suculento; garantia de qualidade (rótulo com origem e procedência); gosto doce (Sólidos Solúveis (SS): 12,0³rix); baixa acidez (Acidez Titulável (AT): 0,980 g ácido cítrico.100 $\mathrm{mL}^{-1}$; SS/AT: 12,24); e que atendeu aos padrões exigidos pelo sistema de Classificação para o melão
(PROGRAMA BRASILEIRO PARA MODERNIZAÇÃO DA HORTICULTURA, 2004), ou seja, tinham sólidos solúveis superior a 9, $0^{\circ}$ Brix; coloração característica da variedade (amarela); e Categoria Extra. Verificou-se que o melão foi muito bem aceito, pois $92 \%$ dos consumidores atribuíram notas 8 e 9 (gostei muito e gostei extremamente, respectivamente) e $8 \%$ atribuíram nota 7 (gostei moderadamente), para o item coloração (Tabela 2).

Em relação ao sabor, $38 \%$ dos entrevistados atribuíram nota máxima ( 9 - gostei extremamente) e $62 \%$ atribuíram notas de 7 a 8 (gostei moderadamente e gostei muito, respectivamente), indicando que o fruto oferecido apresentava boa qualidade organoléptica (Tabela 2 ).

Também 38\% dos entrevistados atribuíram a nota 9 para o item suculência. A nota mais baixa foi 7, a qual perfez apenas $3 \%$ dos consumidores. Estes resultados indicam que o melão apresentado estava de acordo com as expectativas indicadas pelo consumidor quando se efetuou o levantamento dos atributos relevantes (Tabela 2).

A avaliação da aparência externa mostra que o lote piloto foi muito bem aceito neste quesito pelos frequentadores do Mercado Municipal, a maior parte dos entrevistados

Tabela 1. Número de respostas obtidas sobre o grau de importância dos itens avaliados no Mercado Municipal de Piracicaba, para definir a qualidade do melão comercializado.

\begin{tabular}{lcccccc}
\hline \multirow{2}{*}{ Itens avaliados } & \multicolumn{5}{c}{ Grau de importância } \\
\cline { 2 - 6 } & NI & PI & AI & I & MI \\
\hline Aparência externa & 1 & 1 & 2 & 24 & 31 \\
Coloração característica & 0 & 2 & 3 & 33 & 22 \\
da variedade (amarela) & & & & & \\
Firmeza & 0 & 1 & 1 & 31 & 27 \\
Suculência & 2 & 2 & 3 & 19 & 34 \\
Preço & 1 & 0 & 6 & 25 & 28 \\
Garantia de qualidade & 0 & 0 & 2 & 28 & 33 \\
Gosto doce & 0 & 0 & 1 & 20 & 39 \\
\hline
\end{tabular}

$\mathrm{NI}=$ Nenhuma Importância; $\mathrm{PI}$ = Pouca Importância; AI = Alguma Importância; $\mathrm{I}$ = Importante; e MI = Muito Importante.

Tabela 2. Distribuição das notas para cada item avaliado no teste piloto em pesquisa realizada no Mercado Municipal de Piracicaba.

\begin{tabular}{ccccc}
\hline \multirow{2}{*}{ Notas } & \multicolumn{4}{c}{$\mathrm{N}^{\circ}$ de respostas para os itens avaliados } \\
\cline { 2 - 5 } & Coloração & Sabor & Suculência & Aparência externa \\
\hline 1 & - & - & - & - \\
2 & - & - & - & - \\
3 & - & - & - & - \\
4 & - & - & - & - \\
5 & - & - & - & - \\
6 & - & - & - & - \\
7 & 27 & 38 & 32 & 24 \\
8 & 65 & 58 & 65 & 75 \\
9 & 8 & 4 & 3 & 1 \\
\hline
\end{tabular}

Obs.: 9 = gostei extremamente; $8=$ gostei muito; 7 = gostei moderadamente; $6=$ gostei ligeiramente; 5 = não gostei nem desgostei; 4 = desgostei ligeiramente; 3 =desgostei moderadamente; 2 = desgostei muito; e 1 = desgostei extremamente. 
(99\%) atribuiu notas satisfatórias, ou seja, acima de 7 (gostei moderadamente) (Tabela 2).

\section{Conclusão}

Conclui-se, portanto, que o método QFD foi eficiente na avaliação do melão amarelo. A pesquisa e o teste hedônico revelaram que os consumidores buscam frutos sem defeitos, que apresentem coloração característica da variedade, textura firme, suculência, garantia de qualidade, preço justo e gosto doce.

Diante da insatisfação dos consumidores e considerando-se que o melão é consumido preferencialmente in natura, deve-se atentar à preservação da sua aparência e qualidade sensorial. A opinião dos consumidores deve ser considerada na tentativa de identificar os pontos que devem ser melhorados dentro da cadeia de comercialização, a fim de minimizar as perdas e promover a melhoria e a manutenção da qualidade do produto final.

\section{Referências bibliográficas}

AGRIANUAL: Anuário da agricultura brasileira. In: São Paulo: FNP Consultoria e Comércio, 2007. p. 400-404.

ANDREUCCETTI, C.; FERREIRA, M. D.; TAVARES, M. Perfil dos consumidores de tomate de mesa em supermercados da região de Campinas. Horticultura Brasileira, v. 23, n. 1, p. 148-153, 2005.

CHENG, L. C. et al. QFD: planejamento da qualidade. Belo Horizonte: Fundação Christiano Ottoni, 1995.

CHITARRA, A. B.; ALVES, R. E. Tecnologia de pós-colheita para frutas tropicais. Fortaleza: FRUTAL - SINDIFRUTA, 2001.

COCHRAN, W. G. Sampling Techniques. New York: John Wiley \& Sons, 1977.

COHEM, R. A.; HICKS, J. R. Effect of storage on quality and sugar in muskmelon. Journal of American Society for Horticultural Science, v. 111, n. 4, p. 553-557, 1986.

FERREIRA, V. L. P. et al. Análise sensorial: testes discriminativos e afetivos. Campinas: SBCTA, 2000.
HORTALIÇA é o primeiro item cortado do cardápio em tempos de crise. Unesp Rural, v. 15, p. 4, 1999.

IASBECK, L. C. A.; OLIVEIRA, F. M. O atendimento ao cliente como forma de maximização do lucro empresarial. Revista Múltipla, v. 10, n. 19, p. 163-185, 2005.

KADER, A. A. Postharvest technology of horticultural crops. Davis: University of California, 2002.

KAYS, S. J. Postharvest physiology of perishable plants products. New York: Van Nostrand Reinhold, 1991.

MACHADO, F. C. A. P. et al. Agribusiness Europeu. São Paulo: Pioneira, 1996.

MARCOS, S. K. Desenvolvimento de tomate de mesa, com o uso do método QFD (Quality Function Deployment), comercializado em um supermercado. Campinas, 2001. 199 p. Tese (Doutorado) Faculdade de Engenharia de Alimentos, Universidade de Campinas - UNICAMP.

MATTAR, F. N. Pesquisa de marketing: metodologia, planejamento. São Paulo: Atlas, 1999.

MEILGAARD, M.; CIVILLE, G. V.; CARR, B. T. Sensory evaluation techniques. Florida: CRC, 1991.

OWEN, K. M.; GRIFFITH, G. R.; WRIGHT, V. E. One little Lebanese cucumber is not going to break the bank: price in the choice of fresh fruits and vegetables. Australian Journal of Agricultural and Resource Economics, v. 46, n. 2, p. 209-231, 2002.

PROGRAMA BRASILEIRO PARA MODERNIZAÇÃO DA HORTICULTURA. Normas de Classificação de Melão. São Paulo: CEAGESP, Centro de Qualidade em Horticultura, 2004. (CQH. Documentos, 27).

RIJ, R. E.; ROSS, S. R. Effects of shrink film warp on internal gas concentrations chilling injury, and ripening of Honeydew melons. Journal of Food Quality, v. 11, p. 175-182, 1988.

SHEWFELT, R. L. Consumer friendly specifications for a global marketplace. Food Australia, v. 52, n. 7, p. 311-314, 2000.

VILELA, N.J.; MACEDO, M.C. Fluxo de poder no agronegócio: o caso das hortaliças. Horticultura Brasileira, v. 18, n. 2, p. 88-94, 2000. 